(1)

CrossMark

\title{
Clinically relevant subgroups in COPD and asthma
}

\author{
Alice M. Turner ${ }^{1,2}$, Lilla Tamasi ${ }^{3}$, Florence Schleich ${ }^{4}$, Mehmet Hoxha $^{5}$, \\ Ildiko Horvath ${ }^{3}$, Renaud Louis ${ }^{4}$ and Neil Barnes ${ }^{6}$
}

Affiliations: ${ }^{1}$ Clinical and Experimental Medicine, University of Birmingham, Queen Elizabeth Hospital Birmingham, Birmingham, UK. ${ }^{2}$ Dept of Respiratory Medicine, Birmingham Heartlands Hospital, Birmingham, UK. ${ }^{3}$ Dept of Pulmonology, Semmelweis University, Budapest, Hungary. ${ }^{4}$ Respiratory Medicine, CHU SartTilman B35, Liege, Belgium. ${ }^{5}$ Service of Allergology and Clinical Immunology, UHC "Mother Teresa”, Tirana, Albania. ${ }^{6}$ GlaxoSmithKline, Stockley Park West, Uxbridge, UK.

Correspondence: Alice M. Turner, Clinical and Experimental Medicine, University of Birmingham, Queen Elizabeth Hospital Birmingham, Mindelsohn Way, Birmingham, B15 2WB, UK. E-mail: a.m.woodabham.ac.uk

ABSTRACT As knowledge of airways disease has grown, it has become apparent that neither chronic obstructive pulmonary disease (COPD) nor asthma is a simple, easily defined disease. In the past, treatment options for both diseases were limited; thus, there was less need to define subgroups. As treatment options have grown, so has our need to predict who will respond to new drugs. To date, identifying subgroups has been largely reported by detailed clinical characterisation or differences in pathobiology. These subgroups are commonly called "phenotypes"; however, the problem of defining what constitutes a phenotype, whether this should include comorbid diseases and how to handle changes over time has led to the term being used loosely.

In this review, we describe subgroups of COPD and asthma patients whose clinical characteristics we believe have therapeutic or major prognostic implications specific to the lung, and whether these subgroups are constant over time. Finally, we will discuss whether the subgroups we describe are common to both asthma and COPD, and give some examples of how treatment might be tailored in patients where the subgroup is clear, but the label of asthma or COPD is not.

@ERSpublications

Summary of subgroups of airways disease that can be found in COPD and asthma, and their management http:///ow.ly/KiDvo

\section{Introduction}

As knowledge of airways disease has grown, it has become apparent that neither chronic obstructive pulmonary disease (COPD) nor asthma is an easily defined disease. Various new definitions have been proposed [1-3], largely focusing on identifying subgroups by detailed clinical characterisation or differences in pathobiology. These subgroups are commonly called "phenotypes" and in some cases correspond with the Oxford English Dictionary definition of a phenotype: "The sum total of the observable characteristics of an individual, regarded as the consequence of the interaction of the individual's genotype with the environment". This definition does not include treatment or prognosis, but has strengths in that it helps us to observe clusters of characteristics and delineate new phenotypes where,

Received: July 212014 | Accepted after revision: Sept 222014

Support statement: This study was not supported by any specific funding, although the authors met and began the process of researching the review at an educational event sponsored by GSK. L. Tamasi has received funding from the Hungarian Respiratory Society. F. Schleich and R. Louis have been supported by the Interuniversity Attraction Poles (IAP) Project, Brussels, Belgium (P6/35 and P7/30).

Conflict of interest: Disclosures can be found alongside the online version of this article at err.ersjournals.com

Provenance: Submitted article, peer reviewed.

Copyright OERS 2015. ERR articles are open access and distributed under the terms of the Creative Commons Attribution Non-Commercial Licence 4.0. 
many years later, further research can lead to treatment. However, the utility of some phenotypes in clinical practice remains uncertain due to inconsistency of definition, accumulation of comorbid diseases, the propensity of both asthma and COPD to change over time, and the lack of a clear relationship with defined treatment strategies.

In this review we describe a series of clinically relevant subgroups in COPD and asthma, i.e. patients with clearly defined clinical characteristics (phenotype) and whom we believe have prognostic or therapeutic implications specific to the lung. Using this definition, commonly associated comorbidities would not be part of the way the subgroup was defined unless the cluster of comorbidities were specific to COPD or asthma, or altered pulmonary management. Behavioural characteristics, such as poor compliance with treatment, would also fall outside our subgroups as they affect many diseases equally. We will also review the evidence for the stability of these subgroups over time, the degree to which they overlap between COPD and asthma, and what this implies for therapy.

\section{Clinically relevant subgroups in COPD}

COPD is an umbrella term covering many underlying processes that may lead to fixed airflow obstruction. Several large clinical trials and cohort studies have begun to delineate COPD subgroups where there is a clear treatment implication (table 1). A number of other subgroups, where the picture regarding treatment is not as clear or which are more clinically relevant because of their implication for prognosis than treatment, are shown in figure 1.

Comorbidity in COPD influences prognosis [29] and health-related quality of life (HRQoL) [30] and shares aspects of pathogenesis [31]. However, there remains considerable debate as to whether comorbid disease represents a specific subgroup. Common comorbidities in COPD include osteoporosis, ischaemic heart disease, anxiety and depression. Most common comorbidities impair outcome in COPD patients, have clear treatment implications if present, and are treated similarly whether the patient has COPD or not (table 2). These treatments are not specific to the underlying airway disease and, thus, do not form part of our definition of a clinically relevant subgroup.

TABLE 1 Subgroups of chronic obstructive pulmonary disease (COPD) that currently have specific treatments

\begin{tabular}{|c|c|c|c|}
\hline Subgroup & Treatment & Effect of treatment & [Ref.] \\
\hline Frequent exacerbator & $\begin{array}{l}\text { LABA, LAMA, LABA/ICS, } \\
\text { roflumilast, macrolides }\end{array}$ & $\begin{array}{l}\text { Reduced exacerbations, } \\
\text { better HRQoL, } \\
\text { improved lung function, } \\
\text { possible effect on } \mathrm{FEV}_{1} \\
\text { decline }^{\text {I }} \text { and mortality }\end{array}$ & {$[4-11]$} \\
\hline Chronic bronchitis & Roflumilast, mucolytics & $\begin{array}{l}\text { Reduced exacerbations, } \\
\text { improved HRQoL }\end{array}$ & [12-14] \\
\hline$\alpha_{1}$-antitrypsin deficiency & $\alpha_{1}$-antitrypsin augmentation & $\begin{array}{l}\text { Reduced progression } \\
\text { of emphysema }\end{array}$ & [15] \\
\hline $\begin{array}{l}\text { Upper zone dominant } \\
\text { emphysema and } \\
\text { bullous emphysema }\end{array}$ & LVRS & $\begin{array}{l}\text { Improved lung function, } \\
\text { reduced exacerbations }\end{array}$ & {$[16,17]$} \\
\hline Type 1 respiratory failure & LTOT & $\begin{array}{l}\text { Improved survival } \\
\text { and HRQoL }\end{array}$ & {$[18,19]$} \\
\hline Type 2 respiratory failure & Domiciliary NIV & $\begin{array}{l}\text { Improved survival, } \\
\text { possible effect on } \\
\text { hospital admissions } \\
\text { and HRQoL }\end{array}$ & [20-24] \\
\hline Eosinophilic COPD\# & Steroids & $\begin{array}{l}\text { Reduced exacerbations, } \\
\text { improved lung function }\end{array}$ & [25-27] \\
\hline Biomass COPD & Removal of biomass exposure & Reduced FEV1 decline & [28] \\
\hline
\end{tabular}

Frequent exacerbator, chronic bronchitis and $\alpha_{1}$-antitrypsin deficiency are stable over time; the other subgroups may vary according to disease severity or evidence is not yet clear. LABA: long-acting $\beta$-agonists; LAMA long-acting muscarinic antagonists; ICS: inhaled corticosteroids; HRQoL; health-related quality of life; FEV1: forced expiratory volume in $1 \mathrm{~s}$; LVRS: lung volume reduction surgery; LTOT: long-term oxygen therapy; NIV: noninvasive ventilation. \# : see "Subgroups shared between COPD and asthma" section; " : effect only reported for LABA/ICS. 


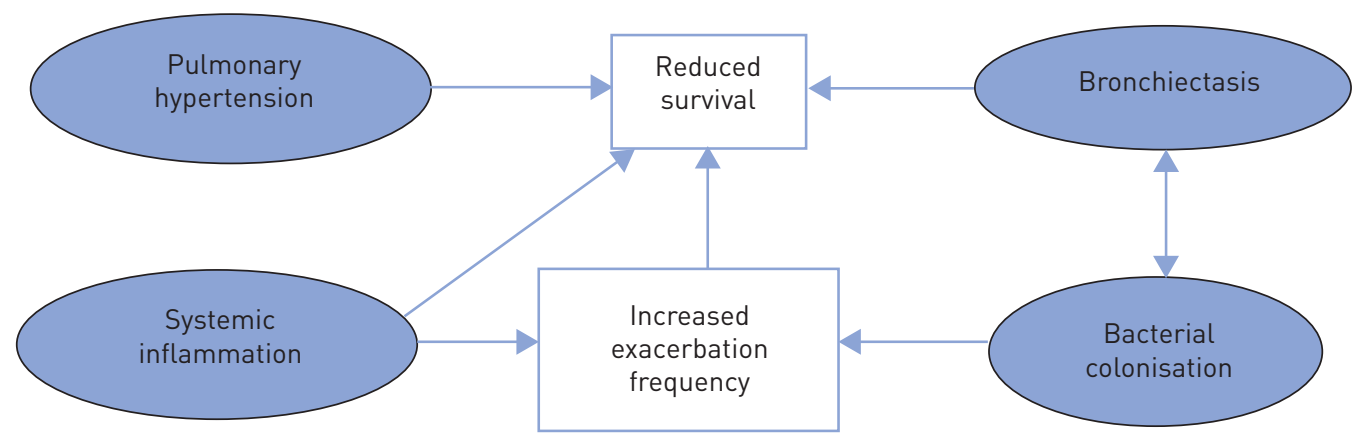

FIGURE 1 Chronic obstructive pulmonary disease subgroups without clear treatment implications. The figure shows the subgroups with clear prognostic implications for patients that are clinically relevant, but where therapeutic strategies are as yet unclear. The directions of the arrows indicate the probable direction of the association, e.g. patients with more frequent exacerbations are less likely to survive. The direction of association of bacterial colonisation and bronchiectasis is not clear; thus, a bidirectional arrow is shown.

The only possible exception to this is osteoporosis, which is almost twice as common in subjects with airflow obstruction compared to those without [48], is particularly associated with emphysema [40] and has been shown to change with pulmonary treatment (e.g. lung volume reduction surgery (LVRS)). A prospective cohort study [49] looking at the effect of LVRS on bone mineral density (BMD) in patients with severe COPD concluded that surgery significantly improved BMD compared to pulmonary rehabilitation. The increase correlated with residual volume, diffusing capacity of the lung for carbon monoxide and fat-free mass, suggesting that restoration of respiratory dynamics, gas exchange and nutritional status induced an improvement in bone metabolism and mineral content independent of exercise. However, changes in BMD could occur with increased activity resulting in the beneficial effect of LVRS and may have confounded results. Furthermore, most interventional studies of osteoporosis outside COPD show more modest BMD improvement, generally in the range of 3-8\% [41], whereas LVRS patients in this study improved by up $24 \%$, suggesting that the result should be interpreted with caution. The degree to which the relationship between osteoporosis and emphysema is confounded by prior steroid treatment is not clear, but there are male patients with little or no steroid exposure who develop osteoporosis, suggesting that it may not be entirely iatrogenic [50]. However, further studies are indicated to understand mechanisms and determine optimal treatment.

TABLE 2 Common comorbidities in chronic obstructive pulmonary disease (COPD)

\begin{tabular}{|c|c|c|c|}
\hline Comorbidity & $\begin{array}{l}\text { Effect/associations of } \\
\text { comorbidity in COPD }\end{array}$ & Treatment & [Ref.] \\
\hline $\begin{array}{l}\text { Ischaemic heart } \\
\text { disease }\end{array}$ & Increased mortality & $\begin{array}{c}\beta \text {-blocker, ACE-I, aspirin, } \\
\text { statin, nitrates }\end{array}$ & {$[32,33]$} \\
\hline $\begin{array}{l}\text { Congestive cardiac } \\
\text { failure }\end{array}$ & $\begin{array}{l}\text { Increased symptom burden, } \\
\text { increased mortality }\end{array}$ & $\begin{array}{c}\text { As above, plus diuretics } \\
\text { Digoxin and implantable } \\
\text { devices may be used in some } \\
\text { patients }\end{array}$ & {$[32,34]$} \\
\hline Anxiety & $\begin{array}{c}\text { Poor HRQoL, increased } \\
\text { mortality, increased hospital } \\
\text { admissions }\end{array}$ & $\begin{array}{c}\text { CBT, benzodiazepines, } \\
\text { exercise }\end{array}$ & [35-37] \\
\hline Depression & $\begin{array}{c}\text { Poor HRQoL, increased } \\
\text { mortality, increased hospital } \\
\text { admissions }\end{array}$ & $\begin{array}{c}\text { CBT, anti-depressants, } \\
\text { exercise }\end{array}$ & [37-39] \\
\hline Osteoporosis & $\begin{array}{l}\text { Reduced physical } \\
\text { performance, poor lung } \\
\text { function }\end{array}$ & $\begin{array}{l}\text { Calcium supplements, } \\
\text { bisphosphonates }\end{array}$ & [40-44] \\
\hline GORD & More frequent exacerbations & PPI, H2 receptor antagonist & [45-47] \\
\hline
\end{tabular}

This is not an exhaustive list of all conditions or treatments; where possible, references specific to COPD, major review articles or international guidelines on management have been cited rather than single studies. GORD: gastro-oesophageal reflux disease; ACE-I: angiotensin-converting enzyme inhibitor; HRQoL: health-related quality of life; CBT: cognitive behavioural therapy, PPI: proton-pump inhibitor. 


\section{Subgroups with implications for treatment}

Frequent exacerbators, defined as those with more than two exacerbations a year, were definitively described in the ECLIPSE (Evaluation of COPD Longitudinally to Identify Predictive Surrogate End-points) study [51]. Treatment options in this group include bronchodilators, long-acting $\beta$-agonists (LABA)/inhaled corticosteroids (ICS), roflumilast and azithromycin. In a number of trials, bronchodilation has been shown to reduce exacerbation frequency. Long-acting muscarinic antagonists (LAMA) appear to exhibit this as a class effect, e.g. tiotropium and glycopyrronium both reduced exacerbation frequency by $>20 \%$ in the GLOW2 trial and were not statistically different in this regard [5]. A meta-analysis of LABAs showed a reduction in exacerbations that was close to $20 \%$, although differences between them were reported; formoterol only reduced exacerbations when used alongside ICS, whereas salmeterol had an effect when used alone [6]. LAMA may be superior to LABA at reducing exacerbations, as shown in the POET (Prevention of Exacerbations of COPD) study (tiotropium versus salmeterol) [11]. LAMA/LABA also reduce exacerbation frequency, although the effect does not appear additive. For example, in the SPARK study (indacaterol and glycopyrronium), the combination only reduced exacerbations by a further $12 \%$ over monotherapy [52]. LABA/ICS have been demonstrated to improve lung function and HRQoL and to reduce exacerbations by $\sim 25 \%$ in COPD patients [7]. Whilst most COPD trials have not focused on frequent exacerbators, international guidelines recognise the impact of certain drug classes on exacerbation frequency, emphasising the role of LABA/ICS [53]. Macrolides have become a hot topic throughout respiratory medicine, primarily because of their potential anti-inflammatory effects. In COPD, the largest study to date used azithromycin and prolonged time to first exacerbation from 174 to 266 days, implying it might be useful in frequent exacerbators [10]. Long-term safety issues include resistance and have been discussed elsewhere [54].

Chronic bronchitis occurs in 45\% of COPD patients [55] and is linked to higher exacerbation frequency and, hence, risk of decline [56]. Specific therapies for patients with chronic bronchitis have been reviewed elsewhere [57]. Roflumilast appears to prevent exacerbations best in COPD patients who have chronic bronchitis [14], although utility may not be restricted to this group. Its use provided modest but significantly improved forced expiratory volume in $1 \mathrm{~s}\left(\mathrm{FEV}_{1}\right)$ compared with placebo and a reduction in exacerbations. Mucolytics have also been used to reduce sputum viscosity and aid expectoration; those most widely used are carbocysteine and $\mathrm{N}$-acetylcysteine. Whilst trials have not been specific to chronic bronchitis, their mechanism of action suggests they will work best in chronic sputum producers. The most recent systematic review of clinical effectiveness of mucolytics included 30 studies and demonstrated a small, but statistically significant, reduction in exacerbations in treated COPD patients [12].

$\alpha_{1}$-antitrypsin deficiency (AATD) is the textbook case of a subgroup in COPD. It is associated with lower zone dominant emphysema [58], although significant heterogeneity exists, possibly due to genetic modifiers, as in usual COPD [59]. Augmentation therapy for AATD has been routinely used in some countries since the first trials were completed; a meta-analysis has demonstrated that it may reduce emphysema progression [15]. Further trials, including inhaled $\alpha_{1}$-antitrypsin, are due to be published soon and other specific therapies may become available in due course [60].

Upper zone dominant emphysema, as defined by visual appearance on chest computed tomography scans, was specifically reported in the NETT (National Emphysema Treatment Trial) study, which demonstrated that LVRS works best in this group of patients [16]. Further research using endobronchial valves as a less invasive means of LVRS initially targeted this group [17]. Post hoc analyses suggest that whether fissures are intact may be more important than disease location or heterogeneity [61]. Patients with upper zone dominant emphysema also exhibit different genetic risk factors, implying variation in pathogenesis [62]. Bullous emphysema is also treated surgically, although patient selection and operative technique is much more individualised [63].

Overt or relative hypoxia occurs in COPD, especially in later stages. The basis for long-term oxygen therapy (LTOT; oxygen for $>15 \mathrm{~h}$ per day) is derived from two landmark placebo-controlled randomised controlled trials, the NOTT (Nocturnal Oxygen Therapy Trial) study [18] and the MRC (Medical Research Council) study [19], which demonstrated improved survival. The NOTT study also demonstrated a decrease in mean pulmonary artery pressure. LTOT is indicated for stable patients who have an arterial oxygen tension $<7.3 \mathrm{kPa}$ on two separate occasions or $7.3-8.0 \mathrm{kPa}$ in the presence of pulmonary hypertension, nocturnal hypoxia or secondary polycythaemia. LTOT is not restricted to type 1 respiratory failure; however, if used in type 2 patients, adverse effects on hypercapnia are generally excluded prior to prescription. Aside from LTOT, two other modes of oxygen therapy exist, ambulatory and short burst; both have been reviewed elsewhere [64]. Ambulatory oxygen is indicated in mobile patients who meet LTOT criteria and is commonly considered in others who exhibit exertional desaturation to $<90 \%$. Short-burst oxygen therapy criteria are poorly defined and no benefits have been reported [65].

Noninvasive ventilation (NIV) is used to treat type 2 respiratory failure and has a strong acute evidence base in hospital [66] for COPD patients. The evidence concerning use of home NIV in COPD is 
contradictory and concerns have been raised about whether potential benefits on incidence of severe exacerbations and hospital admissions are appropriately balanced with poor HRQoL [20-23]. More recently, it has been shown to improve survival by $21 \%$ [24]; a systematic review is ongoing [67].

Eosinophilic COPD is a controversial area, mainly because of the issue of whether it is truly distinct from asthma (overlap pathologies will be discussed later). Recent evidence suggests it may be identified by sputum cytokine profile [68]. Nevertheless, trials focussing on such patients have been published and suggest that steroids are more beneficial in this group than in other COPD patients [25]. Several studies have reported that use of sputum eosinophilia as a guide to the use of steroids was effective [26, 27, 69], and systemic eosinophil counts may also be a useful guide to treating exacerbations with oral corticosteroids [70]. Recent evidence suggests that blood eosinophil counts $>2 \%$ predicted a response to ICS in several major COPD trials [71], although these were post hoc analyses and further definitive work in this area is awaited.

Biomass fuel COPD is common in females, particularly in the developing world [72]. Airway predominant phenotypes appear to be more common, with bronchial hyperresponsiveness (BHR) being a particular feature in wood smoke exposure [73]. Consistent with this is the reported increased prevalence of an overlap between asthma and COPD [74]. Systemic and pulmonary inflammation is similar to cigarette smoke-induced disease [75, 76], with less emphysema [77] and less rapid FEV1 decline [78]. Patients decline more slowly if the biomass exposure is reduced [28], but is not clear whether inhaled therapies used for "usual COPD" are of similar efficacy. The presence of BHR and overlap with asthma suggests that ICS might be an effective strategy, though no clinical trials have been reported yet.

\section{Subgroups with less clear implications for therapy}

Pulmonary hypertension in COPD adversely affects survival and exercise capacity. Although oxygen therapy protects against progression of pulmonary hypertension in patients with advanced COPD, its use is limited to those meeting LTOT criteria. Vasoactive compounds used in primary pulmonary hypertension (sildenafil, bosentan and nitric oxide) have been investigated in COPD [79-83]. Some trials showed worsening HRQoL in treated patients, hence they are not used routinely, although individual patient trials are employed in selected patients by specialist centres [84].

Systemic inflammation appeared to mark a subgroup of patients in the ECLIPSE study. This subgroup comprised $16 \%$ of the whole group and had increased mortality and exacerbation rates compared to patients without inflammation [85]. It remains unclear whether this group should be treated differently; future trials of therapies aimed at reducing exacerbations might target this group, or include them as a pre-specified subgroup analysis.

Stable state airway bacterial colonisation occurs in 30-70\% of COPD patients, and may relate to sputum colour [86-88]. It is defined as a significant pathogenic bacterial load (usually $>1 \times 10^{6} \mathrm{cfu} \cdot \mathrm{mL}^{-1}$ ) present in sputum when the patient is well. Airway bacterial colonisation is associated with increased pulmonary inflammation [89] and increased frequency of exacerbations [90]; hence, it seems a logical subtype to target. Differences between laboratories, local bacterial patterns and lack of consistency of culture results over time may impact significantly on our ability to use this as a phenotype that directs therapy. Moxifloxacin has been tested to limited clinical benefit (exacerbation rates did not fall, although changes in bacteriology were seen) [91], and a macrolide trial is ongoing [92].

There is growing recognition that bronchiectasis may occur in patients who have had COPD for some time, but its prevalence varies widely (30-70\% of subjects), depending on the presence of AATD and the method used to define bronchiectasis on computed tomography [93, 94]. Again it is unclear whether treatment should differ, even though there are implications for survival (COPD with bronchiectasis versus COPD without bronchiectasis, hazard ratio 2.54) [95] and recovery time from exacerbations [96]. Exacerbation frequency has not been found to differ $[95,96]$, although colonisation is more common [96].

Airflow obstruction, aetiology of which is thought to be due to tuberculosis [97], is a poorly defined phenotype as it is not clear whether the underlying prognosis is the same as classical smoking-related COPD or whether treatment should differ. It is likely that pathogenesis differs, but this has not been investigated fully. Many clinicians will adopt treatment approaches outside the guidelines for "usual COPD", but it remains important to emphasise to non-specialists that not all fixed airflow obstruction is "usual COPD". Early life events that impact on lung function [98] seem unlikely to be amenable to therapy later in life, but this too remains uncertain.

\section{Constancy of COPD subgroups}

In general, COPD is regarded as a disease that is slowly progressive; thus, it should be relatively easy to select a treatment at a given time-point that will remain useful for some time. However, there has been little research into the progression of the subgroups we have proposed. It may be much harder to propose 
a specific therapy for those that vary unless very detailed monitoring is undertaken or the duration of therapy is fixed.

There are a number of COPD subgroups that remain constant once present. The frequent exacerbator subgroup was relatively stable in the ECLIPSE study [51], as was systemic inflammation [85]. Whilst therapies that target exacerbations may reduce their frequency [4], this positive treatment effect does not detract from the fact that patients on a range of treatments in the ECLIPSE study still exhibited stable exacerbation frequency, enabling it to be considered a sufficiently stable feature to guide treatment. Chronic bronchitis is defined as sputum production on most days for at least 3 months within at least 2 consecutive years [99], and consequently is probably constant enough to guide therapy. By definition, AATD is a constant phenotype as it is determined by genotype.

Other subgroups appear to develop over time but are sufficiently constant to guide therapy decisions over a few years. Upper zone dominant emphysema has not been studied longitudinally in usual COPD; however, in AATD, it is an early event prior to the development of lower zone dominant emphysema followed by homogenous disease [100]. This occurs over many years; thus, it is probably constant enough to guide decision making on treatment such as chronic bronchitis. Longitudinal blood gas studies have not been commonly carried out in COPD, although type 2 failure does develop over time, occurring in $24 \%$ of patients who have had an acidotic hypercapnic exacerbation 5 years after the first event [101]. Predictors of hypoxia and hypercapnia include lung function and body composition [102]. What data are available suggest that progression of blood gas changes occurs in COPD, but that changes are slow enough (outside exacerbations) to enable gases to be used to guide therapy.

Phenotypes where variation occurs over time are also seen in COPD. Pulmonary hypertension usually occurs late in disease [103], although it can occur alongside mild COPD [104]. Probably the only relevant clinical feature to define constancy is whether it is ever reported to disappear once it has developed; intuitively one would imagine that it is as constant as the degree of respiratory failure though this is not supported by published evidence. One small study has shown that pulmonary artery pressure varies with exacerbations and exercise [105]; animal studies also imply phases of remission [106]. There have been few published studies detailing longitudinal changes in sputum bacterial content in stable COPD. Data in AATD suggests that it does not always stay the same [107], Moraxella catarrhalis and Pseuodomonas aeruginosa are capable of spontaneous remission in COPD [108, 109], and serial cultures during clinical trials also demonstrate variability [10]. It seems unlikely that colonisation can be defined on the basis of a single sputum culture when stable, but it might become a sufficiently constant phenotype to guide therapy if the definition can be better clarified.

\section{Clinically relevant subgroups in asthma}

Bronchial asthma is a complex disease with many underlying mechanisms and, therefore, can be considered a syndrome containing subgroups with important similarities but also differences caused by variable underlying aetiologies [1]. Some subgroups described in the literature are based on clinical features found in asthma databases and cluster analyses; molecular and genetic approaches have also been widely used [110]. This merging of clinical and pathological features has been reviewed extensively elsewhere [111], using the term endotype to delineate this way of defining disease. Within this review, we have chosen to focus on clinically relevant subgroups rather than endotypes, as this may be more useful in clinical practice, although discussion of some molecular elements is unavoidable.

\section{Subgroups with treatment implications}

A number of distinct asthma phenotypes have treatment implications and are summarised in table 3. There is a degree of overlap in that aspirin-sensitive asthma (ASA), which is caused by increased cysteinyl leukotriene production exacerbated by nonsteroidal anti-inflammatory drugs, is often accompanied by severe eosinophilic rhinosinusitis and nasal polyps. Therefore, it has many features of atopic/allergic asthma, which is often eosinophilic, and is associated with elevated IgE, exhaled nitric oxide fraction (FeNO) and periostin levels [125]. Nonatopic, noneosinophilic asthma typically demonstrates lower airway hyperresponsiveness [126, 127] and lower corticosteroid responsiveness [127].

Based on cluster analysis [128], age at disease onset is a key differentiating factor linked to underlying genetic/molecular features, although it does not influence treatment directly. Nevertheless, it is clear that certain asthma subgroups, which vary with age, will require different treatment. Early-onset asthma is often more atopic/allergic, and ORMDL3 polymorphisms exhibit a stronger association with childhood and severe asthma $[129,130]$. These observations suggest that there are different disease mechanisms in younger patients, which have been partly proven by studies of airway cells. Four inflammatory subgroups are distinguishable in induced sputum: eosinophilic, neutrophilic, paucigranulocytic and mixed granulocytic [131]. For the purposes of treatment, this tends to be divided into eosinophilic and noneosinophilic disease. Supporting this simplified sub-division, molecular phenotyping showed a 
TABLE 3 Asthma subgroups and their stability over time

\begin{tabular}{lcc} 
Subgroup & Treatment & [Ref.] \\
\hline $\begin{array}{l}\text { Atopic/allergic } \\
\text { Eosinophilic }\end{array}$ & Avoidance of triggers, ICS, CS, anti-IgE, anti-IL-5, anti-IL-13 & {$[112-114]$} \\
Non-eosinophilic & Avoidance of triggers, ICS, CS, anti-IgE, anti-IL-5, anti-IL-13 & {$[115]$} \\
ABPA and SAFS & Macrolides, less likely to respond well to ICS & {$[116,117]$} \\
Churg-Strauss syndrome & Antifungals & {$[118,119]$} \\
Exercise-induced asthma & Steroids, cyclophosphamide, rituximab & {$[120,121]$} \\
Aspirin sensitive & ICS & {$[122]$} \\
Occupational & Avoidance of aspirin, leukotriene inhibition & {$[123]$} \\
\end{tabular}

Aspirin sensitive and occupational subgroups appear to stay the same over time; other subgroups may vary according to treatment or the clinical picture is unclear. In each subgroup, some of the treatment options and relevant references are shown (see text for further details). All have shown either symptomatic improvement, reduction in exacerbations or both. Bronchodilator agents are not listed and should be used in all subgroups when required or other therapies with equal efficacy should be used. ABPA: allergic bronchopulmonary aspergillosis; SAFS: severe asthma with fungal sensitisation; ICS: inhaled corticosteroids; CS: corticosteroid; IL: interleukin.

T-helper (Th)2-high gene signature in airway epithelial tissue in 50\% of mild asthmatics, and was associated with more atopy and response to ICS therapy [132]. The remaining patients showed a Th2-low gene signature similar to healthy controls, with less airway obstruction, lower hyperreactivity and lower response to ICS. This implies that selection could be applied to the use of ICS and, in particular, high-dose ICS, based on airway eosinophilia. Trials using this strategy have had some success [115], and it is supported by the latest severe asthma guidelines [114]. Newer drugs targeting severe eosinophilic asthma are also emerging; most are monoclonal antibodies that are likely to be used in highly selected populations. Examples include mepolizumab (anti-interleukin (IL)-5) [115], and lebrikizumab (anti-IL-13), the latter being useful in patients with elevated periostin [113]. However, the relationship between eosinophilia and other features of asthma, such as airway hyperresponsiveness, is by no means clear cut; indeed, they may be inherited separately [133], hence this cannot be the only way in which we define our phenotypes and design new treatments. Noneosinophilic disease has shown some response to macrolide therapy [116, 117], although this is not a widely recommended treatment strategy [114].

Other clinical features can be used to identify patients who fall into subgroups that may influence management. For instance, early-onset allergic, exercise-induced asthma (EIA) and ASA phenotypes belong to the Th2-high form of disease while neutrophilic asthma and smooth-muscle mediated paucigranulocytic asthma belong to the non-Th2 group [110]. Sputum cell counts may be impractical for routine phenotyping, particularly in primary care; hence, a detailed history (age of onset, atopy, aspirin sensitivity, smoking, etc.) is key to identifying subgroups and tailoring treatment in clinical practice. In allergic asthma, avoidance of triggers may be a strategy, although the utility of avoidance for house dust mite allergy is debatable [134]. Omalizumab is a well-validated strategy for allergic asthma with high IgE, which reduces corticosteroid use and exacerbation rates [135] and improves long-term control [136]. Patients with ASA should avoid aspirin and nonsteroidal anti-inflammatory drugs. Although there is some evidence that leukotriene inhibition is particularly effective in ASA, it is not consistent [123, 137] and standard asthma management should be followed.

History also identifies occupational asthma, which is best diagnosed by the occupational asthma system score on serial peak expiratory flow rate testing or specific provocation challenge [138]. It is subdivided into asthma precipitated by the exposure or pre-existing asthma that is worsened by exposure. Sputum eosinophil counts and FeNO relate reasonably well to specific provocation challenge [139], although distinct groups without FeNO elevation are identifiable [140]. Cessation or reduction of exposure is key, as delineated in a systematic review by a European Respiratory Society Task Force [124]. Patients with continued exposure tend to progress faster in terms of lung function decline and symptoms [141].

Fungal sensitisation in asthma is common with an estimated prevalence of up to $30 \%$ [142], covering a spectrum from allergic bronchopulmonary aspergillosis (ABPA) through severe asthma with fungal sensitisation (SAFS) and asymptomatic sensitisation. Diagnosis is made by examining serum IgE, and by performing specific radioallergosorbent tests to Aspergillus and Aspergillus precipitins. Both ABPA and SAFS respond to antifungals $[118,119]$, although their efficacy is debatable [114]. Susceptibility to fungal infection and sensitisation may be genetically determined (e.g. human leukocyte antigen type [143] and Toll-like receptors [144]). 
Churg-Strauss syndrome is a rare, progressive, systemic disorder characterised by eosinophilia, extravascular necrotising granulomas, worsening asthma, lung infiltrates and eventually antineutrophil cytoplasmic antibody-positive systemic vasculitis [145]. Significant heterogeneity is seen at presentation and longer term. Lower baseline eosinophil counts predict mortality [146]. Precise management differs according to disease severity (e.g presence of glomerulonephritis), but in general involves aggressive immunosuppression, often with cylophosphamide alongside corticosteroids [120]. Rituximab has also been used with some success [121].

EIA is an acute transient airway narrowing that occurs during and, most often, after exercise. EIA is defined as a decrease in $\mathrm{FEV} 1>10 \%$ from baseline measured up $30 \mathrm{~min}$ after exercise. A higher prevalence of EIA has been reported among elite athletes, especially in endurance sports, such as rowing and cross-country skiing, compared to the general population [147]. However, some elite athletes with EIA have neither a history of childhood asthma nor a family history of asthma, suggesting that environmental factors are more important than genetic inheritance [148]. The most effective therapy for EIA is regular use of ICS [122]. Early use of leukotriene inhibition may be equally effective [149, 150].

\section{Subgroups with less clear implications for therapy}

Severe refractory asthma is an area of intense research, which many newer therapies are being targeted towards. However, this is also heterogeneous with eosinophilic and noneosinophilic phenotypes [151], implying that severity may not be the feature that drives specific treatment. Nevertheless, at least part of severe asthma has a different pathobiology compared to nonsevere disease. For example, innate immunity in the airway is influenced by glucocorticoids [152] and there have been recent insights into the role that innate immunity plays in steroid refractory severe disease [153].

Neutrophilic asthma also exhibits some innate immune features [154], although whether this is a true phenotype remains debatable. Neutrophilic asthma is associated with low FEV1, air trapping [155] and smoking [156], and thus may represent overlap with COPD, or indeed with other pro-inflammatory trigger factors. For instance, two studies have reported clusters of older, obese, female, nonatopic asthmatics $[128,157]$. "Extensive remodelling asthma" is characterised by pronounced airway remodelling and minimal inflammation [158], increased airway smooth muscle mass may also occur. One cause may be an intrinsic airway smooth muscle abnormality. Whether extensive remodelling has therapeutic implications remains uncertain.

\section{Reconciling variability and triggers with subgroup identification}

Unlike COPD, asthma is classically thought to be variable. This brings problems when defining subgroups, as patients may change over time or in response to treatment. We suggest that identifying the current subgroup is the most important factor when modulating therapy. Knowing the subgroup at initial diagnosis may also help but past features should not preclude altering treatment based on current presentation.

\section{Triggers}

Specific trigger or detrimental factors are interesting elements of phenotyping. Classical triggers (allergens and occupation) that change treatment are part of our subgroup definitions. Recognised triggers that do not alter specific asthma management include obesity, smoking, gastro-oesophageal reflux disease (GORD), menstrual cycle and air pollution. Obesity is a risk factor for asthma, and asthma often causes weight gain; there is no consensus about the exact relationship between the two. One cluster analysis identified a noneosinophilic obese group of patients [128], another has reported a nonatopic obese group who required multiple courses of corticosteroids [157]. However, a recent meta-analysis reported that body mass index (BMI) was a key feature of asthma subgroups but, of the clusters that were predominantly obese, clinical and inflammatory differences occurred between them suggesting heterogeneity independent of obesity [159]. Weight loss appears to help asthma control [160]; however, since weight loss has pluripotent health benefits, we felt it did not represent specific asthma management. Smoking also influences the course of asthma. Asthmatics who smoke show poor response to corticosteroid therapy, more frequent exacerbations and worse lung function progressing to fixed obstruction, but smoking might make airways disease worse.

An association between asthma and GORD has been the subject of considerable investigation. There is no doubt that GORD is more common in asthma [161] and this has led to the suggestion that reflux treatment may improve asthma control. Several large clinical trials [162,163] and a Cochrane review [164] have been published, demonstrating that treatment with high-dose proton-pump inhibitor improves cough but has no effect on asthma symptoms, lung function or exacerbation rates. 
$17 \%$ of asthmatic females report worsening of symptoms near menses, and this perimenstrual asthma phenotype is associated with higher BMI, lower forced vital capacity, GORD, aspirin sensitivity and poor asthma control [165]. However, healthy females exhibit similar changes in pulmonary physiology across their menstrual cycle to those with asthma [166], and multivariate analysis has shown that baseline asthma characteristics can differ in those who report symptom changes across their cycle [167]. As such, it is likely that sex hormones represent a trigger, and that perimenstrual asthma is not a truly different subtype.

\section{Constancy of asthma subgroups}

The constancy of asthma phenotypes over time, or after therapy implementation, is not as clear in COPD. Asthma is variable, thus phenotypes ought to change over time, but few published data exist. Those that appear to remain constant are occupational asthma and ASA. Occupational asthma progresses faster if exposure continues [124], implying that the underlying disease process is unchanged. The risk of precipitating severe exacerbations means that testing whether patients remain aspirin sensitive long-term has rarely been performed. Case reports demonstrate that aspirin sensitivity can develop in patients who have previously taken it without respiratory problems [168], but studies which have challenged known ASA patients have shown that most remain sensitive $[169,170]$. Asthma subgroups that clearly change with treatment include ABPA, SAFS and Churg-Strauss syndrome. Atopy and allergy may also remit, usually over time but occasionally with treatment, such as desensitisation [171]. For example, 21\% of children aged $<2$ years with severe peanut allergy will be tolerant by 5 years of age [172]. Remission of asthma was equally common in allergic/atopic and nonatopic patients in a large prospective cohort study of childhood-onset asthma, averaging $65 \%$ of patients [173]. Even in adults, allergic responses vary over time, as demonstrated by the fact that $39 \%$ of patients have different results on serial skin-prick testing (mostly gaining new allergies), but in $13 \%$ of cases allergies were lost and in $4 \%$ allergies were gained and lost [174].

Published evidence is inconsistent regarding the constancy of asthmatic airway inflammation. In adults, $50 \%$ of mild-to-moderate asthmatics have persistently noneosinophilic (often neutrophilic) disease and the remainder have persistent or intermittent eosinophilia [175]. Intermittent and persistent groups exhibited similar clinical characteristics, and hence may represent a milder form of the same population. Therapeutically, the neutrophilic patients respond poorly to usual asthma therapy. Conversely, the sputum inflammatory phenotype proved inconsistent in asthmatic children [176]. This may also change with treatment; for example, corticosteroids inhibit neutrophil apoptosis [177] such that neutrophilic asthma could actually represent over-treated eosinophilic asthma. This hypothesis is supported by the observation that corticosteroid withdrawal abolished neutrophilic subjects among moderate asthmatics [156].

\section{Subgroups shared between COPD and asthma}

When a patient presents with symptoms of increased variability of airflow alongside partially reversible airflow obstruction, it is known as the asthma-COPD overlap syndrome (ACOS) [178]. A consensus conference has proposed that an ACOS patient must fulfil two major criteria or one major and two minor criteria from the following. 1) Major criteria: positive bronchodilator response ( $>400 \mathrm{~mL}$ and $>15 \% \mathrm{FEV} 1)$, sputum eosinophilia or previous diagnosis of asthma. 2) Minor criteria: increased total serum IgE, history of atopy or positive bronchodilator test $(>200 \mathrm{~mL}$ and $>12 \% \mathrm{FEV} 1)$ on at least two occasions [179]. ACOS typically includes patients with early-onset asthma and a long disease duration who then fulfil criteria for COPD with age, COPD patients with increased reversibility and smoking asthmatics who have fixed airflow obstruction. Overall, 13-19\% of patients with obstructive lung diseases have some overlap and this increases with age $[180,181]$. In the UPLIFT (Understanding Potential Long-term Impacts of Tiotropium) trial, two-thirds of moderate-to-severe COPD patients exhibited bronchodilator responsiveness [182]; however, most clinical trials for either asthma or COPD exclude patients with features of the other disease, implying that their results will be poorly generalisable in real-life. ACOS has been extensively reviewed elsewhere $[178,179]$. Our reasoning for including it here is to revisit the concept in light of the more complex subgroups of both asthma and COPD that we have described. Its importance is that patients exhibiting features consistent with ACOS are more likely to be frequent exacerbators [183], have more respiratory symptoms, higher mortality [183], higher comorbidity rates [184], greater healthcare utilisation [184] and worse HRQoL [181].

Overlap patients are generally thought to exhibit phenotypes part way between COPD and asthma. For example, GiBSON and SIMPSON [178] reported prevalence of atopy that was highest in asthma (100\%) intermediate in ACOS (64\%) and lowest in COPD (25\%). There are some differences that may depend on the predominant pathology. Positive bronchodilator response observed in COPD is associated with increased eosinophilic inflammation [185] whilst irreversible COPD more frequently exhibits neutrophilia. Smoking asthmatics typically have inflammatory features that resemble COPD with increased neutrophilia and sometimes airway remodelling [186]. Classical asthma drivers, such as occupation, are associated with fixed airflow obstruction after chronic exposure [187] and ABPA has also been reported in patients with COPD [188]. 


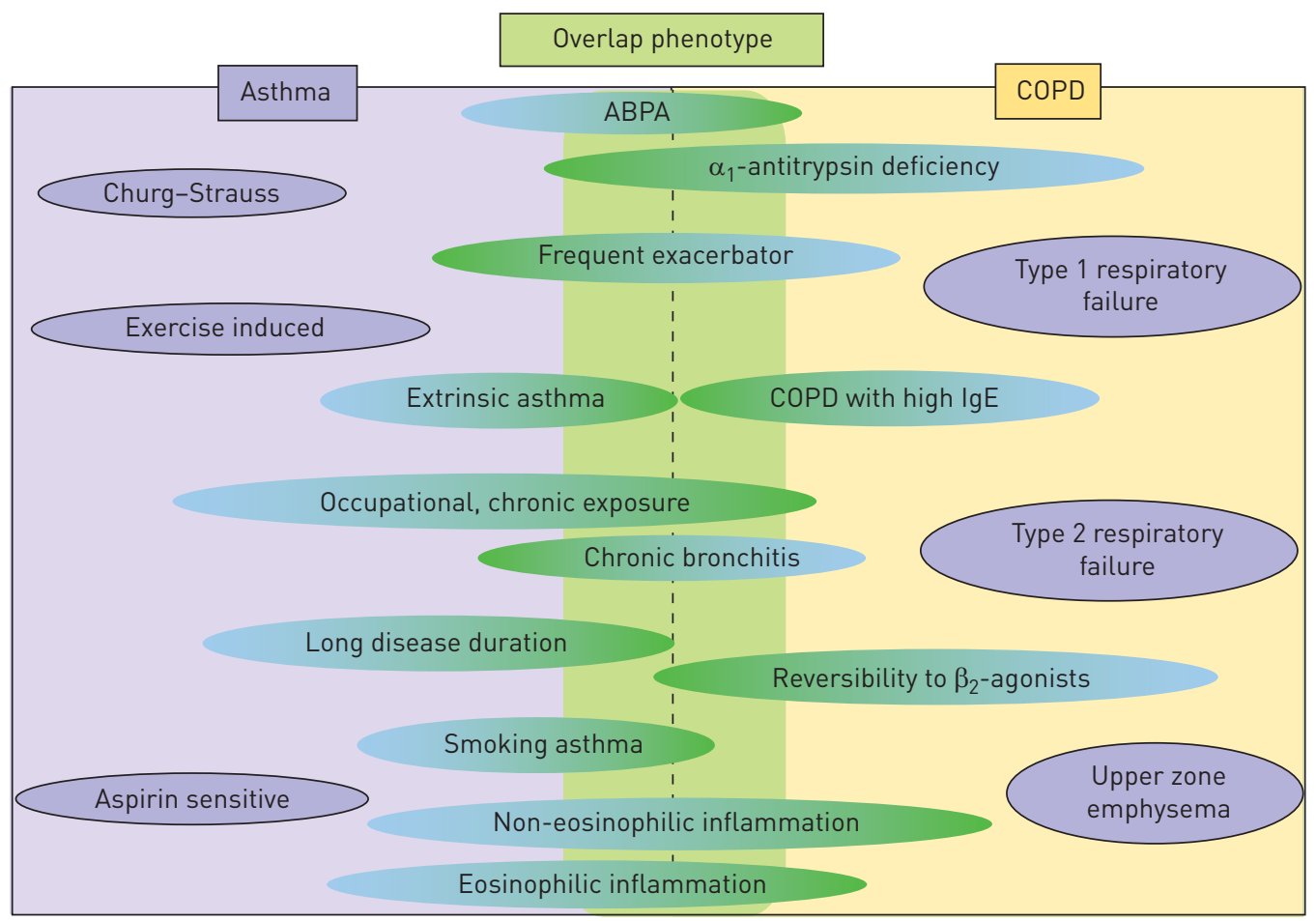

FIGURE 2 Schematic diagram of the shared subgroups between asthma and chronic obstructive pulmonary disease (COPD). The figure shows phenotypes that are recognised in both conditions. The placement/colour of the shapes indicates the degree to which they are recognised in asthma and COPD. ABPA: allergic bronchopulmonary aspergillosis.

During exacerbations of ACOS, airway mucosal eosinophils increase more than neutrophils [189] explaining the improvement with systemic corticosteroids or ICS. Conversely, analysis of volatile organic compounds in severe persistent asthma compared to severe COPD showed that volatile organic compound patterns remained different, suggesting singular pathophysiological mechanisms [190]. Taken together, the evidence suggests that there may be aspects of shared pathogenesis that move treatment decisions to that of the subgroup irrespective of the primary diagnosis. Shared subgroups are shown in figure 2.

\section{Examples of subgroups common to asthma and COPD}

The evidence for treating overlap is far less extensive than for single pathology. In addition, it would be beyond the scope of this article to review all shared subgroups comprehensively; thus, we have chosen a few pertinent examples. One significant shared phenotype where evidence exists for management is eosinophilic airways disease. The evidence that asthmatics with eosinophilia respond to steroids is incontrovertible, and a study from Leicester, UK, has demonstrated that patients with COPD and relatively high blood eosinophils ( $>2 \%$ ) respond better to oral steroids in the context of an exacerbation than those with lower levels [70]. Similar results have been reported for use of ICS [25-27, 69].

Frequent exacerbations in asthma can be associated with risk factors such as severe nasal sinus disease, GORD, recurrent respiratory infections and obstructive sleep apnoea [191]. Many, such as GORD, are similar to the risk factors for frequent exacerbation in COPD patients in the ECLIPSE study [51]. Similar strategies to manage risk factors are advocated in both diseases, alongside potential additional therapies such as macrolides [10, 116, 192].

\section{Messages for clinical practice}

Characterising patients with chronic respiratory symptoms may be more important than giving a label of asthma or COPD in predicting prognosis and response to treatment. A lot of phenotypes have been defined in the literature but some of them do not yet have treatment or prognostic implications. Asthma subgroups, unlike COPD, are likely to change over time and the current phenotype should be regarded as the most important factor to guide treatment.

\section{Acknowledgements}

We would like to thank GSK for organising the European Respiratory Network of Excellence event that stimulated the debates leading to this review. 


\section{References}

1 Lotvall J, Akdis CA, Bacharier LB, et al. Asthma endotypes: a new approach to classification of disease entities within the asthma syndrome. J Allergy Clin Immunol 2011; 127: 355-360.

2 Han MK, Agusti A, Calverley PM, et al. Chronic obstructive pulmonary disease phenotypes: the future of COPD. Am J Respir Crit Care Med 2010; 182: 598-604.

3 Parr DG. Patient phenotyping and early disease detection in chronic obstructive pulmonary disease. Proc Am Thorac Soc 2011; 8: 338-349.

4 Wedzicha JA, Rabe KF, Martinez FJ, et al. Efficacy of roflumilast in the COPD frequent exacerbator phenotype. Chest 2013; 143: 1302-1311.

5 Kerwin E, Hébert J, Gallagher N, et al. Efficacy and safety of NVA237 versus placebo and tiotropium in patients with COPD: the GLOW2 study. Eur Respir J 2012; 40: 1106-1114.

6 Wang J, Nie B, Xiong W, et al. Effect of long-acting beta-agonists on the frequency of COPD exacerbations: a meta-analysis. J Clin Pharm Ther 2012; 37: 204-211.

$7 \quad$ Nannini LJ, Lasserson TJ, Poole P. Combined corticosteroid and long-acting $\beta_{2}$-agonist in one inhaler versus long-acting $\beta_{2}$-agonists for chronic obstructive pulmonary disease. Cochrane Database Syst Rev 2012; 9: CD006829.

8 Celli BR, Thomas NE, Anderson JA, et al. Effect of pharmacotherapy on rate of decline of lung function in chronic obstructive pulmonary disease: results from the TORCH study. Am J Respir Crit Care Med 2008; 178: 332-338.

9 Calverley PM, Anderson JA, Celli B, et al. Salmeterol and fluticasone propionate and survival in chronic obstructive pulmonary disease. N Engl J Med 2007; 356: 775-789.

10 Albert RK, Connett J, Bailey WC, et al. Azithromycin for prevention of exacerbations of COPD. N Engl J Med 2011; 365: 689-698.

11 Vogelmeier C, Hederer B, Glaab T, et al. Tiotropium versus salmeterol for the prevention of exacerbations of COPD. N Engl J Med 2011; 364: 1093-1103.

12 Poole P, Black PN, Cates CJ. Mucolytic agents for chronic bronchitis or chronic obstructive pulmonary disease. Cochrane Database Syst Rev 2012; 8: CD001287.

13 Fabbri LM, Calverley PM, Izquierdo-Alonso JL, et al. Roflumilast in moderate-to-severe chronic obstructive pulmonary disease treated with long-acting bronchodilators: two randomised clinical trials. Lancet 2009; 374: 695-703.

14 Rennard SI, Calverley PM, Goehring UM, et al. Reduction of exacerbations by the PDE4 inhibitor roflumilast the importance of defining different subsets of patients with COPD. Respir Res 2011; 12: 18.

15 Stockley RA, Parr DG, Piitulainen E, et al. Therapeutic efficacy of $\alpha-1$ antitrypsin augmentation therapy on the loss of lung tissue: an integrated analysis of 2 randomised clinical trials using computed tomography densitometry. Respir Res 2010; 11: 136.

16 Fishman A, Martinez F, Naunheim K, et al. A randomized trial comparing lung-volume-reduction surgery with medical therapy for severe emphysema. N Engl J Med 2003; 348: 2059-2073.

17 Sciurba FC, Ernst A, Herth FJ, et al. A randomized study of endobronchial valves for advanced emphysema. N Engl J Med 2010; 363: 1233-1244.

18 Continuous or nocturnal oxygen therapy in hypoxemic chronic obstructive lung disease: a clinical trial. Nocturnal Oxygen Therapy Trial Group. Ann Intern Med 1980; 93: 391-398.

19 Long term domiciliary oxygen therapy in chronic hypoxic cor pulmonale complicating chronic bronchitis and emphysema. Report of the Medical Research Council Working Party. Lancet 1981; 1: 681-686.

20 Budweiser S, Hitzl AP, Jôrres RA, et al. Impact of noninvasive home ventilation on long-term survival in chronic hypercapnic COPD: a prospective observational study. Int J Clin Prac 2007; 61: 1516-1522.

21 Budweiser S, Jorres RA, Riedl T, et al. Predictors of survival in COPD patients with chronic hypercapnic respiratory failure receiving noninvasive home ventilation. Chest 2007; 131: 1650-1658.

22 McEvoy RD, Pierce RJ, Hillman D, et al. Nocturnal non-invasive nasal ventilation in stable hypercapnic COPD: a randomised controlled trial. Thorax 2009; 64: 561-566.

23 Funk GC, Breyer MK, Burghuber OC, et al. Long-term non-invasive ventilation in COPD after acute-on-chronic respiratory failure. Respir Med 2011; 105: 427-434.

24 Köhnlein T, Windisch W, Köhler D, et al. Non-invasive positive pressure ventilation for the treatment of severe stable chronic obstructive pulmonary disease: a prospective, multicentre, randomised, controlled clinical trial. Lancet Respir Med 2014; 2: 698-705.

25 Siva R, Green RH, Brightling CE, et al. Eosinophilic airway inflammation and exacerbations of COPD: a randomised controlled trial. Eur Respir J 2007; 29: 906-913.

26 Kitaguchi Y, Komatsu Y, Fujimoto K, et al. Sputum eosinophilia can predict responsiveness to inhaled corticosteroid treatment in patients with overlap syndrome of COPD and asthma. Int J Chron Obstruct Pulmon Dis 2012; 7: 283-289.

27 Brightling CE, Monteiro W, Ward R, et al. Sputum eosinophilia and short-term response to prednisolone in chronic obstructive pulmonary disease: a randomised controlled trial. Lancet 2000; 356: 1480-1485.

28 Zhou Y, Zou Y, Li X, et al. Lung function and incidence of chronic obstructive pulmonary disease after improved cooking fuels and kitchen ventilation: a 9-year prospective cohort study. PLoS Med 2014; 11: e1001621.

29 Divo M, Cote C, de Torres JP, et al. Comorbidities and risk of mortality in patients with chronic obstructive pulmonary disease. Am J Respir Crit Care Med 2012; 186: 155-161.

30 Sundh J, Stallberg B, Lisspers K, et al. Co-morbidity, body mass index and quality of life in COPD using the Clinical COPD Questionnaire. COPD 2011; 8: 173-181.

31 Tan SL, Wood AM. Chronic obstructive pulmonary disease and co-morbidities: a review and consideration of pathophysiology. Panminerva Med 2009; 51: 81-93.

32 Cavailles A, Brinchault-Rabin G, Dixmier A, et al. Comorbidities of COPD. Eur Respir Rev 2013; 22: 454-475.

33 Montalescot G, Sechtem U, Achenbach S, et al. 2013 ESC guidelines on the management of stable coronary artery disease: the Task Force on the management of stable coronary artery disease of the European Society of Cardiology. Eur Heart J 2013; 34: 2949-3003.

34 Yancy CW, Jessup M, Bozkurt B, et al. 2013 ACCF/AHA guideline for the management of heart failure: a report of the American College of Cardiology Foundation/American Heart Association Task Force on practice guidelines. Circulation 2013; 128: e240-e327. 

and chronic obstructive pulmonary disease (COPD): a systematic review and meta-analysis. Chest 2013; 144: 766-777.

36 Coventry PA, Gellatly JL. Improving outcomes for COPD patients with mild-to-moderate anxiety and depression: a systematic review of cognitive behavioural therapy. Br J Health Psychol 2008; 13: 381-400.

37 Coventry PA, Bower P, Keyworth C, et al. The effect of complex interventions on depression and anxiety in chronic obstructive pulmonary disease: systematic review and meta-analysis. PLoS One 2013; 8: e60532.

38 Yohannes AM, Alexopoulos GS. Depression and anxiety in patients with COPD. Eur Respir Rev 2014; 23: 345-349.

39 Yohannes AM, Connolly MJ, Baldwin RC. A feasibility study of antidepressant drug therapy in depressed elderly patients with chronic obstructive pulmonary disease. Int J Geriatr Psychiatry 2001; 16: 451-454.

40 Romme EA, Murchison JT, Edwards LD, et al. CT-measured bone attenuation in patients with chronic obstructive pulmonary disease: relation to clinical features and outcomes. J Bone Miner Res 2013; 28 : 1369-1377. Khosla S, Bilezikian JP, Dempster DW, et al. Benefits and risks of bisphosphonate therapy for osteoporosis. J Clin Endocrinol Metab 2012; 97: 2272-2282.

42 Smith BJ, Laslett LL, Pile KD, et al. Randomized controlled trial of alendronate in airways disease and low bone mineral density. Chron Respir Dis 2004; 1: 131-137.

43 Nordin BE. The effect of calcium supplementation on bone loss in 32 controlled trials in postmenopausal women. Osteoporos Int 2009; 20: 2135-2143.

44 Li LS, Caughey GE, Johnston KN. The association between co-morbidities and physical performance in people with chronic obstructive pulmonary disease: a systematic review. Chron Respir Dis 2014; 11: 3-13.

45 Sakae TM, Pizzichini MM, Teixeira PJ, et al. Exacerbations of COPD and symptoms of gastroesophageal reflux: a systematic review and meta-analysis. J Bras Pneumol 2013; 39: 259-271.

46 Sigterman KE, van Pinxteren B, Bonis PA, et al. Short-term treatment with proton pump inhibitors, H2-receptor antagonists and prokinetics for gastro-oesophageal reflux disease-like symptoms and endoscopy negative reflux disease. Cochrane Database Syst Rev 2013; 5: CD002095.

Sasaki T, Nakayama K, Yasuda H, et al. A randomized, single-blind study of lansoprazole for the prevention of exacerbations of chronic obstructive pulmonary disease in older patients. J Am Geriatr Soc 2009; 57: $1453-1457$.

in DD, Man JP, Man SF. The risk of osteoporosis in Caucasian men and women with obstructive airways disease. Am J Med 2003; 114: 10-14.

49 Mineo TC, Ambrogi V, Mineo D, et al. Bone mineral density improvement after lung volume reduction surgery for severe emphysema. Chest 2005; 127: 1960-1966.

50 Duckers JM, Evans BA, Fraser WD, et al. Low bone mineral density in men with chronic obstructive pulmonary disease. Respir Res 2011; 12: 101.

51 Hurst JR, Vestbo J, Anzueto A, et al. Susceptibility to exacerbation in chronic obstructive pulmonary disease. N Engl J Med 2010; 363: 1128-1138.

52 Wedzicha JA, Decramer M, Ficker JH, et al. Analysis of chronic obstructive pulmonary disease exacerbations with the dual bronchodilator QVA149 compared with glycopyrronium and tiotropium (SPARK): a randomised, double-blind, parallel-group study. Lancet Respir Med 2013; 1: 199-209.

53 Global Initiative for Obstructive Lung Disease. Global Strategy for the Diagnosis, Management and Prevention of COPD. www.goldcopd.com Date last accessed: April 2014.

54 Simoens S, Laekeman G, Decramer M. Preventing COPD exacerbations with macrolides: a review and budget impact analysis. Respir Med 2013; 107: 637-648.

55 Izquierdo-Alonso JL, Rodriguez-Gonzalezmoro JM, de Lucas-Ramos P, et al. Prevalence and characteristics of three clinical phenotypes of chronic obstructive pulmonary disease (COPD). Respir Med 2013; 107: 724-731.

56 Donaldson GC, Seemungal TA, Bhowmik A, et al. Relationship between exacerbation frequency and lung function decline in chronic obstructive pulmonary disease. Thorax 2002; 57: 847-852.

57 Kim V, Criner GJ. Chronic bronchitis and chronic obstructive pulmonary disease. Am J Respir Crit Care Med 2013; 187: 228-237.

58 Laurell CB, Eriksson S. The serum alpha-l-antitrypsin in families with hypo-alpha-L-antitrypsinemia. Clin Chim Acta 1965; 11: 395-398.

59 Wood AM, Simmonds MJ, Bayley DL, et al. The TNF- $\alpha$ gene relates to clinical phenotype in $\alpha-1$-antitrypsin deficiency. Respir Res 2008; 9: 52.

60 Stockley RA, Turner AM. $\alpha$-1-antitrypsin deficiency: clinical variability, assessment, and treatment. Trends Mol Med 2014; 20: 105-115.

61 Herth FJ, Noppen M, Valipour A, et al. Efficacy predictors of lung volume reduction with Zephyr valves in a European cohort. Eur Respir J 2012; 39: 1334-1342.

62 DeMeo DL, Hersh CP, Hoffman EA, et al. Genetic determinants of emphysema distribution in the national emphysema treatment trial. Am J Respir Crit Care Med 2007; 176: 42-48.

63 Greenberg JA, Singhal S, Kaiser LR. Giant bullous lung disease: evaluation, selection, techniques, and outcomes. Chest Surg Clin N Am 2003; 13: 631-649.

64 Stoller JK, Panos RJ, Krachman S, et al. Oxygen therapy for patients with COPD: current evidence and the long-term oxygen treatment trial. Chest 2010; 138: 179-187.

65 O'Neill B, Mahon JM, Bradley J. Short-burst oxygen therapy in chronic obstructive pulmonary disease. Respir Med 2006; 100: 1129-1138.

66 British Thoracic Society Standards of Care Committee.: Non-invasive ventilation in acute respiratory failure. Thorax. 2002; 57: 192-211.

67 Dave C, Turner A, Dretzke J, et al. Protocol for a systematic review and economic evaluation of the clinical and cost-effectiveness of non-hospital-based non-invasive ventilation (NIV) in patients with stable end-stage COPD with hypercapnic respiratory failure. Syst Rev 2014; 3: 32.

68 Ghebre MA, Bafadhel M, Desai D, et al. Biological clustering supports both "Dutch" and "British" hypotheses of asthma and chronic obstructive pulmonary disease. J Allergy Clin Immunol 2015; 135: 63-72.

69 Brightling CE, McKenna S, Hargadon B, et al. Sputum eosinophilia and the short term response to inhaled mometasone in chronic obstructive pulmonary disease. Thorax 2005; 60: 193-198. 
Bafadhel M, McKenna S, Terry S, et al. Blood eosinophils to direct corticosteroid treatment of exacerbations of chronic obstructive pulmonary disease: a randomized placebo-controlled trial. Am J Respir Crit Care Med 2012; 186: 48-55.

Barnes N. Old data for a new paradigm. Eur Respir J 2014; 44: Suppl. 58, p1547.

Po JY, FitzGerald JM, Carlsten C. Respiratory disease associated with solid biomass fuel exposure in rural women and children: systematic review and meta-analysis. Thorax 2011; 66: 232-239.

Gonzalez-Garcia M, Torres-Duque CA, Bustos A, et al. Bronchial hyperresponsiveness in women with chronic obstructive pulmonary disease related to wood smoke. Int J Chron Obstruct Pulmon Dis 2012; 7: 367-373.

Golpe R, Sanjuan Lopez P, Cano Jimenez E, et al. Distribution of clinical phenotypes in patients with chronic obstructive pulmonary disease caused by biomass and tobacco smoke. Arch Bronconeumol 2014; 50: 318-324.

Hu G, Zhou Y, Hong W, et al. Development and systematic oxidative stress of a rat model of chronic bronchitis and emphysema induced by biomass smoke. Exp Lung Res 2013; 39: 229-240.

Aksu F, Capan N, Aksu K, et al. C-reactive protein levels are raised in stable chronic obstructive pulmonary disease patients independent of smoking behavior and biomass exposure. J Thorac Dis 2013; 5: 414-421.

Camp PG, Ramirez-Venegas A, Sansores RH, et al. COPD phenotypes in biomass smoke- versus tobacco smoke-exposed Mexican women. Eur Respir J 2014; 43: 725-734.

Ramirez-Venegas A, Sansores RH, Quintana-Carrillo RH, et al. FEV1 decline in patients with chronic obstructive pulmonary disease associated with biomass exposure. Am J Respir Crit Care Med 2014; 190: 906-1002

Vonbank K, Ziesche R, Higenbottam TW, et al. Controlled prospective randomised trial on the effects on pulmonary haemodynamics of the ambulatory long term use of nitric oxide and oxygen in patients with severe COPD. Thorax 2003; 58: 289-293.

Stolz D, Rasch H, Linka A, et al. A randomised, controlled trial of bosentan in severe COPD. Eur Respir J 2008; 32: 619-628.

Valerio G, Bracciale P, Grazia D'Agostino A. Effect of bosentan upon pulmonary hypertension in chronic obstructive pulmonary disease. Ther Adv Respir Dis 2009; 3: 15-21.

Rao RS, Singh S, Sharma BB, et al. Sildenafil improves six-minute walk distance in chronic obstructive pulmonary disease: a randomised, double-blind, placebo-controlled trial. Indian J Chest Dis Allied Sci 2011; 53: 81-85. crossover trial. COPD 2012; 9: 268-275.

Hurdman J, Condliffe R, Elliot CA, et al. Pulmonary hypertension in COPD: results from the ASPIRE registry. Eur Respir J 2013; 41: 1292-1301.

Agusti A, Edwards LD, Rennard SI, et al. Persistent systemic inflammation is associated with poor clinical outcomes in COPD: a novel phenotype. PLoS One 2012; 7: e37483.

Miravitlles M, Marin A, Monso E, et al. Colour of sputum is a marker for bacterial colonisation in chronic obstructive pulmonary disease. Respir Res 2010; 11: 58.

Marín A, Monsó E, Garcia-Nuñez M, et al. Variability and effects of bronchial colonisation in patients with moderate COPD. Eur Respir J 2010; 35: 295-302.

Marin A, Garcia-Aymerich J, Sauleda J, et al. Effect of bronchial colonisation on airway and systemic inflammation in stable COPD. COPD 2012; 9: 121-130.

Sethi S, Maloney J, Grove L, et al. Airway inflammation and bronchial bacterial colonization in chronic obstructive pulmonary disease. Am J Respir Crit Care Med 2006; 173: 991-998.

Patel IS, Seemungal TA, Wilks M, et al. Relationship between bacterial colonisation and the frequency, character, and severity of COPD exacerbations. Thorax 2002; 57: 759-764.

Miravitlles M, Marín A, Monsó E, et al. Efficacy of moxifloxacin in the treatment of bronchial colonisation in COPD. Eur Respir J 2009; 34: 1066-1071.

Uzun S, Djamin RS, Kluytmans J, et al. Influence of macrolide maintenance therapy and bacterial colonisation on exacerbation frequency and progression of COPD (COLUMBUS): study protocol for a randomised controlled trial. Trials 2012; 13: 82.

O'Brien C, Guest PJ, Hill SL, et al. Physiological and radiological characterisation of patients diagnosed with chronic obstructive pulmonary disease in primary care. Thorax 2000; 55: 635-642.

Parr DG, Guest PG, Reynolds JH, et al. Prevalence and impact of bronchiectasis in alpha1-antitrypsin deficiency. Am J Respir Crit Care Med 2007; 176: 1215-1221.

Martinez-Garcia MA, de la Rosa Carrillo D, Soler-Cataluna JJ, et al. Prognostic value of bronchiectasis in patients with moderate-to-severe chronic obstructive pulmonary disease. Am J Respir Crit Care Med 2013; 187: 823-831.

Patel IS, Vlahos I, Wilkinson TM, et al. Bronchiectasis, exacerbation indices, and inflammation in chronic obstructive pulmonary disease. Am J Respir Crit Care Med 2004; 170: 400-407.

Ehrlich RI, Adams S, Baatjies R, et al. Chronic airflow obstruction and respiratory symptoms following tuberculosis: a review of South African studies. Int J Tuberc Lung Dis 2011; 15: 886-891.

Bush A. COPD: a pediatric disease. COPD 2008; 5: 53-67. Medical Research Council by their Committee on the Aetiology of Chronic Bronchitis. Lancet 1965; 1: 775-779.

Holme J, Stockley JA, Stockley RA. Age related development of respiratory abnormalities in non-index $\alpha-1$ antitrypsin deficient studies. Respir Med 2013; 107: 387-393.

Costello R, Deegan P, Fitzpatrick M, et al. Reversible hypercapnia in chronic obstructive pulmonary disease: a distinct pattern of respiratory failure with a favorable prognosis. Am J Med 1997; 102: 239-244.

Saure EW, Eagan TM, Jensen RL, et al. Explained variance for blood gases in a population with COPD. Clin Respir J 2012; 6: 72-80.

Andersen $\mathrm{KH}$, Iversen M, Kjaergaard J, et al. Prevalence, predictors, and survival in pulmonary hypertension related to end-stage chronic obstructive pulmonary disease. J Heart Lung Transplant 2012; 31: 373-380.

Hurdman J, Condliffe R, Elliot CA, et al. Pulmonary hypertension in COPD: results from the ASPIRE registry. Eur Respir J 2013; 41:1292-1301.

, Ideura G, Ito $\mathrm{M}$, et al. Pulmonary haemodynamic changes in patients with severe COPD. Respirology 2008; 13: 919-922. 
Bonnet S, Savineau JP, Barillot W, et al. Role of $\mathrm{Ca}^{2+}$-sensitive $\mathrm{K}^{+}$channels in the remission phase of pulmonary hypertension in chronic obstructive pulmonary diseases. Cardiovasc Res 2003; 60: 326-336.

Wood AM, Bharadwa P, Bayley D, et al. Bacterial colonisation in alpha-1 antitrypsin deficiency. Eur Respir J 2008; 32: Suppl., 52, E4496.

Murphy TF, Brauer AL, Grant BJ, et al. Moraxella catarrhalis in chronic obstructive pulmonary disease: burden of disease and immune response. Am J Respir Crit Care Med 2005; 172: 195-199.

Murphy TF, Brauer AL, Eschberger K, et al. Pseudomonas aeruginosa in chronic obstructive pulmonary disease. Am J Respir Crit Care Med 2008; 177: 853-860.

Wenzel SE. Asthma phenotypes: the evolution from clinical to molecular approaches. Nat Med 2012; 18: 716-725. Anderson GP. Endotyping asthma: new insights into key pathogenic mechanisms in a complex, heterogeneous disease. Lancet 2008; 372: 1107-1119.

Pavord ID, Korn S, Howarth P, et al. Mepolizumab for severe eosinophilic asthma (DREAM): a multicentre, double-blind, placebo-controlled trial. Lancet 2012; 380: 651-659.

Corren J, Lemanske RF, Hanania NA, et al. Lebrikizumab treatment in adults with asthma. N Engl J Med 2011; 365: 1088-1098.

Chung KF, Wenzel SE, Brozek JL, et al. International ERS/ATS guidelines on definition, evaluation and treatment of severe asthma. Eur Respir J 2014; 43: 343-373.

Green RH, Brightling CE, McKenna S, et al. Asthma exacerbations and sputum eosinophil counts: a randomised controlled trial. Lancet 2002; 360: 1715-1721.

Piacentini GL, Peroni DG, Bodini A, et al. Azithromycin reduces bronchial hyperresponsiveness and neutrophilic airway inflammation in asthmatic children: a preliminary report. Allergy Asthma Proc 2007; 28: 194-198.

Brusselle GG, Vanderstichele C, Jordens P, et al. Azithromycin for prevention of exacerbations in severe asthma (AZISAST): a multicentre randomised double-blind placebo-controlled trial. Thorax 2013; 68: 322-329.

Pasqualotto AC, Powell G, Niven R, et al. The effects of antifungal therapy on severe asthma with fungal sensitization and allergic bronchopulmonary aspergillosis. Respirology 2009; 14: 1121-1127.

Denning DW, O’Driscoll BR, Powell G, et al. Randomized controlled trial of oral antifungal treatment for severe asthma with fungal sensitization: the Fungal Asthma Sensitization Trial (FAST) study. Am J Respir Crit Care Med 2009; 179: 11-18.

Cohen P, Pagnoux C, Mahr A, et al. Churg-Strauss syndrome with poor-prognosis factors: a prospective multicenter trial comparing glucocorticoids and six or twelve cyclophosphamide pulses in forty-eight patients. Arthritis Rheum 2007; 57: 686-693.

Cartin-Ceba R, Keogh KA, Specks U, et al. Rituximab for the treatment of Churg-Strauss syndrome with renal involvement. Nephrol Dial Transplant 2011; 26: 2865-2871.

Koh MS, Tee A, Lasserson TJ, et al. Inhaled corticosteroids compared to placebo for prevention of exercise induced bronchoconstriction. Cochrane Database Syst Rev 2007; 3: CD002739.

Micheletto C, Tognella S, Visconti M, et al. Montelukast $10 \mathrm{mg}$ improves nasal function and nasal response to aspirin in ASA-sensitive asthmatics: a controlled study vs placebo. Allergy 2004; 59: 289-294.

Vandenplas O, Dressel H, Nowak D, et al. What is the optimal management option for occupational asthma? Eur Respir Rev 2012; 21: 97-104.

Jia G, Erickson RW, Choy DF, et al. Periostin is a systemic biomarker of eosinophilic airway inflammation in asthmatic patients. J Allergy Clin Immunol 2012; 130: 647-654.

Suh DI, Lee JK, Kim CK, et al. Bronchial hyperresponsiveness to methacholine and adenosine $5^{\prime}$-monophosphate, and the presence and degree of atopy in young children with asthma. Clin Exp Allergy 2011; 41: 338-345.

Green RH, Brightling CE, Woltmann G, et al. Analysis of induced sputum in adults with asthma: identification of subgroup with isolated sputum neutrophilia and poor response to inhaled corticosteroids. Thorax 2002; 57: 875-879.

Haldar P, Pavord ID, Shaw DE, et al. Cluster analysis and clinical asthma phenotypes. Am J Respir Crit Care Med 2008; 178: 218-224.

Moffatt MF, Gut IG, Demenais F, et al. A large-scale, consortium-based genomewide association study of asthma. N Engl J Med 2010; 363: 1211-1221.

Wan YI, Shrine NR, Soler Artigas M, et al. Genome-wide association study to identify genetic determinants of severe asthma. Thorax 2012; 67: 762-768.

Simpson JL, Scott R, Boyle MJ, et al. Inflammatory subtypes in asthma: assessment and identification using induced sputum. Respirology 2006; 11: 54-61.

Woodruff PG, Modrek B, Choy DF, et al. T-helper type 2-driven inflammation defines major subphenotypes of asthma. Am J Respir Crit Care Med 2009; 180: 388-395.

Gray L, Peat JK, Belousova E, et al. Family patterns of asthma, atopy and airway hyperresponsiveness: an epidemiological study. Clin Exp Allergy 2000; 30: 393-399.

4 MacDonald C, Sternberg A, Hunter PR. A systematic review and meta-analysis of interventions used to reduce exposure to house dust and their effect on the development and severity of asthma. Environ Health Perspect 2007; 115: 1691-1695.

5 Rodrigo GJ, Neffen H, Castro-Rodriguez JA. Efficacy and safety of subcutaneous omalizumab vs placebo as add-on therapy to corticosteroids for children and adults with asthma: a systematic review. Chest 2011; 139: 28-35.

Eisner MD, Zazzali JL, Miller MK, et al. Longitudinal changes in asthma control with omalizumab: 2-year interim data from the EXCELS Study. J Asthma 2012; 49: 642-648.

7 Pauls JD, Simon RA, Daffern PJ, et al. Lack of effect of the 5-lipoxygenase inhibitor zileuton in blocking oral aspirin challenges in aspirin-sensitive asthmatics. Ann Allergy Asthma Immunol 2000; 85: 40-45.

Francis HC, Prys-Picard CO, Fishwick D, et al. Defining and investigating occupational asthma: a consensus approach. Occup Environ Med 2007; 64: 361-365.

Lemiere C, D’Alpaos V, Chaboillez S, et al. Investigation of occupational asthma: sputum cell counts or exhaled nitric oxide? Chest 2010; 137: 617-622.

0 Moore VC, Anees W, Jaakkola MS, et al. Two variants of occupational asthma separable by exhaled breath nitric oxide level. Respir Med 2010;104: 873-879.

1 Anees W, Moore VC, Burge PS. FEV1 decline in occupational asthma. Thorax 2006; 61: 751-755. 
142 Maurya V, Gugnani HC, Sarma PU, et al. Sensitization to Aspergillus antigens and occurrence of allergic bronchopulmonary aspergillosis in patients with asthma. Chest 2005; 127: 1252-1259.

143 Chauhan B, Santiago L, Kirschmann DA, et al. The association of HLA-DR alleles and T cell activation with allergic bronchopulmonary aspergillosis. J Immunol 1997; 159: 4072-4076.

144 Carvalho A, Pasqualotto AC, Pitzurra L, et al. Polymorphisms in toll-like receptor genes and susceptibility to pulmonary aspergillosis. J Infect Dis 2008; 197: 618-621.

145 Pagnoux C, Guilpain P, Guillevin L. Churg-Strauss syndrome. Curr Opin Rheumatol 2007; 19: 25-32.

146 Comarmond C, Pagnoux C, Khellaf M, et al. Eosinophilic granulomatosis with polyangiitis (Churg-Strauss): clinical characteristics and long-term followup of the 383 patients enrolled in the French Vasculitis Study Group cohort. Arthritis Rheum 2013; 65: 270-281.

147 Langdeau JB, Turcotte H, Bowie DM, et al. Airway hyperresponsiveness in elite athletes. Am J Respir Crit Care Med 2000; 161: 1479-1484.

148 Ali Z, Norsk P, Ulrik CS. Mechanisms and management of exercise-induced asthma in elite athletes. J Asthma 2012; 49: 480-486.

149 Philip G, Villaran C, Pearlman DS, et al. Protection against exercise-induced bronchoconstriction two hours after a single oral dose of montelukast. J Asthma 2007; 44: 213-217.

150 Duong M, Amin R, Baatjes AJ, et al. The effect of montelukast, budesonide alone, and in combination on exercise-induced bronchoconstriction. J Allergy Clin Immunol 2012; 130: 535-539.

151 Lemiere C, Ernst P, Olivenstein R, et al. Airway inflammation assessed by invasive and noninvasive means in severe asthma: eosinophilic and noneosinophilic phenotypes. J Allergy Clin Immunol 2006; 118: 1033-1039.

152 Zhang N, Truong-Tran QA, Tancowny B, et al. Glucocorticoids enhance or spare innate immunity: effects in airway epithelium are mediated by CCAAT/enhancer binding proteins. J Immunol 2007; 179: 578-589.

153 Bhavsar P, Hew M, Khorasani N, et al. Relative corticosteroid insensitivity of alveolar macrophages in severe asthma compared with non-severe asthma. Thorax 2008; 63: 784-790.

154 Simpson JL, Grissell TV, Douwes J, et al. Innate immune activation in neutrophilic asthma and bronchiectasis. Thorax 2007; 62: 211-218.

155 Busacker A, Newell JD Jr., Keefe T, et al. A multivariate analysis of risk factors for the air-trapping asthmatic phenotype as measured by quantitative CT analysis. Chest 2009; 135: 48-56.

156 Cowan DC, Cowan JO, Palmay R, et al. Effects of steroid therapy on inflammatory cell subtypes in asthma. Thorax 2010; 65: 384-390.

157 Moore WC, Meyers DA, Wenzel SE, et al. Identification of asthma phenotypes using cluster analysis in the Severe Asthma Research Program. Am J Respir Crit Care Med 2010; 181: 315-323.

158 Mauad T, Silva LF, Santos MA, et al. Abnormal alveolar attachments with decreased elastic fiber content in distal lung in fatal asthma. Am J Respir Crit Care Med 2004; 170: 857-862.

159 Sutherland ER, Goleva E, King TS, et al. Cluster analysis of obesity and asthma phenotypes. PLoS One 2012; 7: e36631.

160 Juel CT, Ali Z, Nilas L, et al. Asthma and obesity: does weight loss improve asthma control? a systematic review. J Asthma Allergy 2012; 5: 21-26.

161 Havemann BD, Henderson CA, El-Serag HB. The association between gastro-oesophageal reflux disease and asthma: a systematic review. Gut 2007; 56: 1654-1664.

162 Scarupa MD, Mori N, Canning BJ. Gastroesophageal reflux disease in children with asthma: treatment implications. Paediatr Drugs 2005; 7: 177-186.

163 Kiljander TO, Junghard O, Beckman O, et al. Effect of esomeprazole $40 \mathrm{mg}$ once or twice daily on asthma: a randomized, placebo-controlled study. Am J Respir Crit Care Med 2010; 181: 1042-1048.

164 Gibson PG, Henry RL, Coughlan JL. Gastro-oesophageal reflux treatment for asthma in adults and children. Cochrane Database Syst Rev 2003; 2: CD001496.

165 Rao CK, Moore CG, Bleecker E, et al. Characteristics of perimenstrual asthma (PMA) and its relation to asthma severity and control: data from the Severe Asthma Research Program. Chest 2013; 143: 984-995.

166 Farha S, Asosingh K, Laskowski D, et al. Effects of the menstrual cycle on lung function variables in women with asthma. Am J Respir Crit Care Med 2009; 180: 304-310.

167 Thornton J, Lewis J, Lebrun CM, et al. Clinical characteristics of women with menstrual-linked asthma. Respir Med 2012; 106: 1236-1243.

168 Abayaratne D, Kurukulaaratchy RJ. Recognising the risk of aspirin-sensitive respiratory disease in a patient with asthma who has previously tolerated aspirin. Prim Care Respir J 2011; 20: 214-217.

169 Makowska JS, Grzegorczyk J, Bienkiewicz B, et al. Systemic responses after bronchial aspirin challenge in sensitive patients with asthma. J Allergy Clin Immunol 2008; 121: 348-354.

170 Mastalerz L, Sanak M, Kumik J, et al. Exhaled eicosanoids following bronchial aspirin challenge in asthma patients with and without aspirin hypersensitivity: the pilot study. J Allergy 2012; 2012: 696792.

171 Stelmach I, Sobocinska A, Majak P, et al. Comparison of the long-term efficacy of 3- and 5-year house dust mite allergen immunotherapy. Ann Allergy Asthma Immunol 2012; 109: 274-278.

172 Ho MH, Wong WH, Heine RG, et al. Early clinical predictors of remission of peanut allergy in children. J Allergy Clin Immunol 2008; 121: 731-736.

173 Burgess JA, Matheson MC, Gurrin LC, et al. Factors influencing asthma remission: a longitudinal study from childhood to middle age. Thorax 2011; 66: 508-513.

174 Aslund N, Thomsen SF, Molgaard E, et al. Changes in skin test reactivity among adults with atopic disease: a 3-year prospective study. Ann Allergy Asthma Immunol 2008; 101: 524-528.

175 McGrath KW, Icitovic N, Boushey HA, et al. A large subgroup of mild-to-moderate asthma is persistently noneosinophilic. Am J Respir Crit Care Med 2012; 185: 612-619.

176 Fleming L, Tsartsali L, Wilson N, et al. Sputum inflammatory phenotypes are not stable in children with asthma. Thorax 2012; 67: 675-681.

177 Kato T, Takeda Y, Nakada T, et al. Inhibition by dexamethasone of human neutrophil apoptosis in vitro. Nat Immun 1995; 14: 198-208.

178 Gibson PG, Simpson JL. The overlap syndrome of asthma and COPD: what are its features and how important is it? Thorax 2009; 64: 728-735. 
179

180

Soler-Cataluna JJ, Cosio B, Izquierdo JL, et al. Consensus document on the overlap phenotype COPD-asthma in COPD. Arch Bronconeumol 2012; 48: 331-337.

Soriano JB, Davis KJ, Coleman B, et al. The proportional Venn diagram of obstructive lung disease: two approximations from the United States and the United Kingdom. Chest 2003; 124: 474-481.

Hardin M, Silverman EK, Barr RG, et al. The clinical features of the overlap between COPD and asthma. Respir Res 2011; 12: 127.

Decramer M, Celli B, Kesten S, et al. Effect of tiotropium on outcomes in patients with moderate chronic obstructive pulmonary disease (UPLIFT): a prespecified subgroup analysis of a randomised controlled trial. Lancet 2009; 374: 1171-1178.

Hospers JJ, Postma DS, Rijcken B, et al. Histamine airway hyper-responsiveness and mortality from chronic obstructive pulmonary disease: a cohort study. Lancet 2000; 356: 1313-1317.

Shaya FT, Dongyi D, Akazawa MO, et al. Burden of concomitant asthma and COPD in a Medicaid population. Chest 2008; 134: 14-19.

Papi A, Romagnoli M, Baraldo S, et al. Partial reversibility of airflow limitation and increased exhaled NO and sputum eosinophilia in chronic obstructive pulmonary disease. Am J Respir Crit Care Med 2000; 162: $1773-1777$. Bumbacea D, Campbell D, Nguyen L, et al. Parameters associated with persistent airflow obstruction in chronic severe asthma. Eur Respir J 2004; 24: 122-128.

Blanc PD. Occupation and COPD: a brief review. J Asthma 2012; 49: 2-4.

Mir E, Shah A. Allergic bronchopulmonary aspergillosis in a patient with chronic obstructive pulmonary disease. Prim Care Respir J 2012; 21: 111-114.

Saetta M, Di Stefano A, Maestrelli P, et al. Airway eosinophilia in chronic bronchitis during exacerbations. Am J Respir Crit Care Med 1994; 150: 1646-1652.

Fens N, Zwinderman AH, van der Schee MP, et al. Exhaled breath profiling enables discrimination of chronic obstructive pulmonary disease and asthma. Am J Respir Crit Care Med 2009; 180: 1076-1082.

ten Brinke A, Sterk PJ, Masclee AA, et al. Risk factors of frequent exacerbations in difficult-to-treat asthma. Eur Respir J 2005; 26: 812-818.

Hahn DL, Plane MB, Mahdi OS, et al. Secondary outcomes of a pilot randomized trial of azithromycin treatment for asthma. PLoS Clin Trials 2006; 1: e11. 